\title{
Experimental Justification of Using Aseptisorb-A and Platelet-Rich Plasma in Endoscopic Treatment of Mold Bleeding Stomach Defects
}

\author{
Evgeniy F. Cherednikov, PhD, ScD; Sergey V. Barannikov; Yuri V. Maleev, PhD, ScD; \\ Konstantin O. Fursov; Tatyana E. Litovkina; Evgeniy I. Zakurdaev, PhD; \\ Evgeniy S. Ovsyannikov, $\mathrm{PhD}^{*}$ \\ Voronezh State Medical University named after N. N. Burdenko \\ Voronezh, the Russian Federation
}

\begin{abstract}
The aim of this study was to investigate the possibility of applying the biologically active draining sorbent Aseptisorb-A in combination with platelet-rich plasma (PRP) to arrest bleeding of mold stomach defects in dogs.

Methods and Results: The experimental study was done on 12 outbred dogs (both sexes). Fibrogastroduodenoscopy (FGDS) was performed on all animals under intravenous anesthesia. During FGDS, two ulcerative defects (pilot and control) were made in the antrum of the stomach at $4-5 \mathrm{~cm}$ distant from each other. Endoscopic hemostasis in pilot ulcers was achieved with the help of pneumatic insufflation of powder-like Aseptisorb-A $(0.3 \mathrm{mg})$ on the bleeding defect with further application of platelet-rich autologous plasma from the animal. Endoscopic treatment of control ulcers was not done; such ulcers were used to estimate the time of spontaneous hemostasis. It was determined that in pilot ulcers after described interventions, bleeding arrest occurred in $3.0|2.5| 4.0 \mathrm{sec}$ (Me|upper quartile|lower quartile) $(P<0.01)$. It was noted that in all pilot ulcers, hemostasis was definitive and there was no recurrence of bleeding. In the control ulcers, bleeding arrest occurred in $29.0|27.5| 30.5 \mathrm{sec}(P<0.01)$. In endoscopic gastroscopy, two cases of the reinitiation of haemorrhages in the form of hematin on ulcers were fixed. The reparative process in pilot ulcers treated with Aseptisorb-A and PRP occurred quicker and more efficiently. Complete healing of pilot ulcers occurred in 8.0|8.0|8.5 days $(P<0.01)$ with formation of a slight sword-cut, which did not destroy the wall of the organ. Complete healing of control ulcers was identified in 15.0|15.0|16.0 days $(P<0.01)$ with formation of a rough scar, which deformed the organ's wall.

Conclusion: Using the biologically active draining sorbent Aseptisorb-A in combination with PRP in endoscopic treatment of mold bleeding in the defects of stomachs accelerates the reparative process, reduces the time of healing in experimental ulcers, improves the quality of healing and does not damage stomach tissue. (International Journal of Biomedicine. 2017;7(4):298-301.)
\end{abstract}

Key Words: mold bleeding $\bullet$ endoscopic hemostasis $\bullet$ Aseptisorb-A $\bullet$ platelet-rich plasma $\bullet$ reparative process

\section{Introduction}

The problem of treating bleeding gastroduodenal ulcers is one of the most challenging in emergency abdominal surgery. Currently, in the treatment of patients with ulcerative gastroduodenal bleeding (GDB), endoscopic hemostasis (EH) is accepted as a first-line treatment modality. ${ }^{(1)}$

However, the results of using already available methods of EH do not fully satisfy surgeons due to the continuing

*Corresponding author: Evgeniy S. Ovsyannikov, PhD. Department of faculty therapy, Voronezh State Medical University named after N.N. Burdenko.Voronezh, Russia.E-mail: ovses@, yandex.ru growth of the number of rebleeding cases. Development of new methods of EH is a topical problem of modern clinical practice. $^{(2-5)}$

In the Voronezh City Center for the treatment of patients with GDB, the endoscopic pneumatic insufflation of granular sorbents has been successfully used for more than 24 years in complex treatment. One of the biologically active drainage sorbents of the new generation is Aseptisorb-A. This sorbent has been successfully used in the treatment of GDB because of its pronounced hydrophilic, cytoprotective, hemostatic, antiinflammatory, analgesic, and antibacterial properties. However, it has been noted that granular sorbents are not endowed with pronounced hemostatic properties and when applied in the form of monotherapy, bleeding recurrences are possible. ${ }^{(6-12)}$ 
A number of authors have noted that it is important not only to stop peptic ulcer bleeding, but also to create the condition for the fast and quality healing of gastroduodenal ulcers. $^{(13-16)}$ The possibility of combined use of biologically active draining sorbents with platelet-rich plasma (PRP) in the treatment of peptic ulcer GDB seems very promising.

The aim of this study was to investigate the possibility of applying the biologically active draining sorbent Aseptisorb-A in combination with PRP to arrest bleeding of mold stomach defects in dogs.

\section{Material and Methods}

The experimental study was done on 12 outbred dogs (both sexes). The weight of the dogs was from $10 \mathrm{~kg}$ to 15 $\mathrm{kg}$. The investigation conforms with the Guide for the Care and Use of Laboratory Animals published by the US National Institutes of Health (NIH Publication No. 85-23, revised 1996).

Fibrogastroduodenoscopy (FGDS) was performed on all animals under intravenous anesthesia (Zoletil 100: $7.5 \mathrm{mg} /$ kg body weight). During FGDS, two ulcerative defects (pilot and control) were made in the antrum of the stomach at $4-5 \mathrm{~cm}$ distant from each other. A $3.0 \mathrm{ml}$ of $96 \%$ alcohol was injected in the submucosal layer of the stomach. At the same time, the animal was intravenously injected with vincristine $(0.01 \mathrm{mg} /$ $\mathrm{kg}$ ). In 3-4 days, all animals had 2 acute ulcerative stomach defects $\left(10 \mathrm{~mm}\right.$ in diameter). ${ }^{(17)}$

In examination of bioptic tissue in pilot and control groups before treatment, the anatomic picture was the same and corresponded to an acute stomach ulcer: nidal mixed cell infiltration of the stroma was noted in the area of the defect. On the surface of the tissue, over a placement of fibrin, the impurity of leucocytes and erythrocytes was evident.

There was a layer of the mucous membrane with nidal edema, vessels and fine-focal haemorrhage. Glands were normal but in some areas, cystophorous ectasia was noted; interferruterous stroma had nidal mixed cell infiltration and edema. Neutral glycoproteins were located irregularly in the superficial layers of the mucous membrane. In order to cause bleeding in pilot and control ulcers, the bottom of the ulcer defect was damaged with the help of kelectome. ${ }^{(18)}$

$\mathrm{EH}$ in pilot ulcers was achieved with the help of pneumatic insufflation of powder-like Aseptisorb-A $(0.3 \mathrm{mg})$ on the bleeding defect with further application of platelet-rich autologous plasma from the animal. Endoscopic treatment of control ulcers was not done; such ulcers were used to estimate the time of spontaneous hemostasis. Time of final hemostasis was measured with a seconds counter.

Endoscopic observations of changes in experimental and control defects were performed every other day. Results of the research were estimated according to time of hemostasis, restoration of recurrent hemorrhage, and to time of healing of ulcer defects. Histological sections were stained with hematoxylin and eosin. Collagenous fibers were identified with the help of fuchsin according to Van-Gizon's method, neutral glycoproteids in the periodic acid-Schiff (PAS) reaction, and argyrophilic fibers using silver nitrate. The stained preparations were examined using a light microscope $(\times 100, \times 400$ magnification $)$.

The statistical analysis was performed using the statistical software Microsoft Excel. The results are presented as median (Me), upper quartile (UQ) and lower quartile (LQ). The Mann-Whitney U-test was used to compare the differences between the two independent groups. The Wilcoxon criterion was used to compare the differences between the paired samples. A probability value of $P<0.05$ was considered statistically significant.

\section{Results}

It was determined that in pilot ulcers after described interventions, bleeding arrest occurred in 3.0|2.5|4.0 sec $(\mathrm{Me}|\mathrm{UQ}| \mathrm{LQ})(P<0.01)$. Sorbent was turned into a hydrogel haemostatic medical composition. It fixed firmly in the area of the defect and protected it from negative factors of gastric juice. It was noted that in all pilot ulcers, hemostasis was definitive and there was no recurrence of bleeding.

In the control ulcers, bleeding arrest occurred in $29.0|27.5| 30.5 \mathrm{sec}(P<0.01)$. In that case, a scarlet quaggy clot was formed. The clot was easily washed with fluid. In endoscopic gastroscopy, two cases of the reinitiation of haemorrhages in the form of hematin on ulcers were fixed. It was not necessary to interfere, bleeding had stopped. In further gastroscopy to control the defects of ulcers, two more episodes of the continuation of haemorrhage in the form of hematin on ulcers were fixed. It was not necessary to interfere, bleeding had stopped.

Studying of reparative actions in the pilot ulcers showed that the reparative process in these ulcers treated with Aseptisorb-A and PRP occurred quicker and more efficiently.

In 3.0|3.0|4.0 days $(P<0.01)$ after endoscopic treatment with Aseptisorb-A and PRP, the defect at the bottom of the ulcer was purified. Pilot ulcers diminished in size to $7.0|6.0| 8.0 \mathrm{~mm}$, and inflammatory conditions in form of edema and hyperemia on the edges of the ulcer were less obvious. The inflammatory process in pilot ulcers remitted completely in 3.5|3.0|4.0 days $(P<0.01)$. First signs of regenerative process in the area of the bottom of pilot ulcers in the form of pieces of granulation tissue were identified in 3.2|3.0|4.0 days $(P<0.01)$. Cystophorous glands with signs of papillary proliferation were identified on microslides of the pilot ulcers. In some microslides, there were a large number of plethorical thin-walled vessels with focal accumulation of lymphocytes and neutrophils in mucous and superficial parts of submucosal layer. This anatomical picture proves the presence of granulation tissue in pilot ulcers.

On microslides of the control ulcers, there were signs of ulcerative injury in the form of desquamation. There were areas of fibrin accumulation with impurity of hemolyzed erythrocytes and leucocytes on the surface of control ulcers. The increased number of neutrophils in connective stroma confirmed an acute inflammatory process. Complete healing of pilot ulcers occurred in $8.0|8.0| 8.5$ days $(P<0.01)$ with formation of a slight sword-cut, which did not destroy the wall of the organ.

In pilot ulcers, the anatomical picture of bioptic tissue 
did not have any pathological changes. Research of cellular and fiberlite elements revealed the signs of reparative processes, which were characterized by enlargement of the absolute and relative number of fibroblasts and enlargement of tender reticular fibers in the subepithelial layer. Cells rich in neutral glycoproteins were in both superficial and deep layers of the mucous membrane. There was a large number of cystophorous glands in the control ulcers. Their epithelium was partially desquamated and filled with heavy pink masses similar to mucous. Proliferation of connective fibers was determined in the submucosal layer.

These results prove a high rate and quality of reparative regeneration in treatment of mold ulcers with Aseptisorb-A in combination with PRP. L. Aruin considers the high rate and quality of reparative regeneration in treatment of mold ulcers to be very important. ${ }^{(19)}$

Purification of the control ulcers occurred in 6.0|6.0|6.0 days $(P<0.01)$; the appearance of granulation in the area of the bottom ulcer defect was detected in 6.0|6.0|7.0 days $(P<0.01)$. Sizes of control ulcers diminished to 8.5|8.0|9.5 $\mathrm{mm}(\mathrm{P}>0.05)$; the edges of the ulcer were still irritated. In $9.0|9.0| 10.0$ days, the inflammatory process decreased, ulcers diminished in sizes to 4.0|3.5|5.0 Mм $(P<0.01)$, and the first signs of epithelialization were revealed. Complete healing of control ulcers was identified in $15.0|15.0| 16.0$ days $(P<0.01)$ with formation of a rough scar, which deformed the organ's wall. In 15 to 17 days, in microslides of control ulcers, there was fibrous degeneration of the mucous membrane in the submucosal layer. This fact indicates formation of a rough cicatricle defect in the healing area.

The effectiveness of treatment with granulated sorbent in combination with PRP of experimental bleeding defects is presented in Table 1.

Table 1.

The effectiveness of treatment with Aseptisorb-A in combination with PRP of experimental bleeding defects

\begin{tabular}{|l|c|c|c|c|c|c|c|}
\hline \multirow{2}{*}{\multicolumn{1}{c|}{ Variable }} & \multicolumn{3}{|c|}{ Pilot ulcers } & \multicolumn{3}{c|}{ Control ulcers } & \multirow{2}{*}{ P } \\
\cline { 2 - 7 } & Me & UQ & LQ & Me & UQ & LQ & \\
\hline Hemostasis, sec & 3.0 & 2.5 & 4.0 & 29.0 & 27.5 & 30.5 & $<0.01$ \\
\hline $\begin{array}{l}\text { Purification of ulcer } \\
\text { defect, day }\end{array}$ & 3.0 & 3.0 & 4.0 & 6.0 & 6.0 & 6.0 & $<0.01$ \\
\hline $\begin{array}{l}\text { Appearance of } \\
\text { granulation, day }\end{array}$ & 3.2 & 3.0 & 4.0 & 6.0 & 6.0 & 7.0 & $<0.01$ \\
\hline $\begin{array}{l}\text { Disappearance of } \\
\text { inflammation, day }\end{array}$ & 3.5 & 3.0 & 4.0 & 9.0 & 9.0 & 10.0 & $<0.01$ \\
\hline $\begin{array}{l}\text { Onset of } \\
\text { epithelialization, day }\end{array}$ & 4.0 & 3.5 & 5.0 & 9.0 & 9.0 & 10.0 & $<0.01$ \\
\hline $\begin{array}{l}\text { Complete healing, } \\
\text { day }\end{array}$ & 8.0 & 8.0 & 8.5 & 15.0 & 15.0 & 16.0 & $<0.01$ \\
\hline
\end{tabular}

\section{Conclusion}

Using the biologically active draining sorbent Aseptisorb-A in combination with PRP allows us to perform reliable hemostasis of mold bleeding in the defects in dogs' stomachs without signs of recurrent bleeding. Use of Aseptisorb-A in combination with PRP in endoscopic treatment of mold bleeding in the defects of stomachs accelerates the reparative process, reduces the time of healing in experimental ulcers, improves the quality of healing and does not damage stomach tissue.

\section{Competing interests}

The authors declare that they have no competing interests.

\section{References}

1. Pedroto I, Dinis-Ribeiro M, Ponchon T. Is timely endoscopy the answer for cost-effective management of acute upper gastrointestinal bleeding? Endoscopy. 2012;44(8):7212. doi: $10.1055 / \mathrm{s}-0032-1310064$.

2. Deryaeva OG, Cherednikov EF. Complex treatment of erosive-ulcerative gastroduodenal bleeding in patients multiprofile hospital. Sistemnyj analiz i upravlenie v biomedicinskih sistemah. 2014;13(3):725-730. [Article in Russian].

3. Cherednikov EF, Deryaeva OG, Adianov VV, Ovchinnikov IF, Popov AV. Modern trends in the prevention and treatment of patients with gastrointestinal hemorrhage in the center. Sistemnyj analiz i upravlenie $\mathrm{v}$ biomedicinskih sistemah. 2014;13(2):426-430. [Article in Russian].

4. Ulcerative gastroduodenal bleeding. National clinical guidelines. Hirurgicheskaja praktika. 2015;2:62-64. [in Russian].

5. Starkov YG, Domarev LV, Shitnikov EA, Russkih AE, Svitina KA. Characteristics and effectiveness of various methods of endoscopic hemostasis for peptic ulcer bleeding. Hirurgija v gastrojenterologii. 2014;6: 34-37. [Article in Russian].

6. Cherednikov EF, Kashurnikova MA, Romantsov MN, Barannikov SV, Bolokhovitinov AE, Gaponenkov DG, Lyubimov PYu. Experimental study of new means of local hemostasis in the treatment of ulcerative bleedings. Nauchnomedicinskij vestnik Central'nogo Chernozem'ja. 2016;65:2733. [Article in Russian].

7. Cherednikov EF, Deryaeva OG, Cherednikov EE, Aianov VV, Bondarenko AA, Yakushev FK. The effectiveness of a modern approach to the treatment of patients with gastroduodenal bleeding in a multi-hospital. Nauchnomedicinskij vestnik Central'nogo Chernozem'ja. 2016;65: 20-25. [Article in Russian].

8. Budnevsky AV, Popov ArtV, Cherednikov EF. Erosiveulcerative defeat stomach and duodenal ulcers in medical patients: prevention of bleeding. Nauchno-medicinskij vestnik Central'nogo Chernozem'ja. 2016;65:64-71. [Article in Russian].

9. Cherednikov EF. The fifteen years of experience in the treatment of patients with ulcerative gastroduodenal bleeding. Zhurnal teoreticheskoj i prakticheskoj mediciny. 2008;5(4):372. [Article in Russian].

10. Cherednikov EF, Stepanyan NA, Lyubykh E N. Morphological modeling of stomach ulcers in the treatment of hydrogels. Novosti klinicheskoj citologii Rossii. 1988;2:66. [Article in Russian]. 
11. Cherednikov EF, Batkaev AR, Baev VE. The reparative regeneration of erosive-ulcerative lesions of the stomach and duodenum in the local treatment of hydrophilic granular sorbents. Sistemnyj analiz i upravlenie v biomedicinskih sistemah. 2005;4(2)224-5. [Article in Russian].

12. Koreyba KA, Usmanov MA, Minabutdinov AR. Sorbents "ASEPTISORB" for patients with diabetic foot syndrome. Prakticheskaya medicina. 2014;5(81):143-51. [Article in Russian].

13. Cherednikov EF, Popov AV, Kashurnikova MA, Adianov VV, Ovchinnikov IF, Deryaeva OG, Popov AV. Method of endoscopic treatment of gastroduodenal ulcers. Voronezh State Med Academy NN. Burdenko. 2013:25322492(31). [in Russian].

14. Adianov VV, Cherednikov EF. Optimization of the treatment of gastroduodenal bleedings in patients with high operational risk. Sistemnyj analiz i upravlenie v biomedicinskih sistemah. 2014;13(4)841-6. [Article in Russian].
15. Baev VE, Kravets BB, Cherednikov EF. Diagnosis of ulcerative forms of stomach cancer. Voronezh: Publishing house of Voronezh State University; 2003:110 pp. [in Russian]. 16. Cherednikov EF, Kunin AA, Cherednikov EE, Moiseeva NS. The role of etiopathogenetic aspects in prediction and prevention of discontinuous-hemorrhagic (Mallory-Weiss) syndrome. EPMA J. 2016;7:7. doi: 10.1186/s13167-016-0056-4. 17. Shalimov SA, Radzikhovskiy AP, Keysevich LV. Manual on experimental surgery. Moscow: Medicina; 1989:175-176. [in Russian].

18. Cherednikov EF, Gryaznov VN, Baev VE, Gaponenkov DG. Modeling of a bleeding stomach ulcer. Problemy sudebnoy mediciny i klinicheskoy praktiki. 1994:17-18. [Article in Russian].

19. Aruin LI. The quality of healing of gastroduodenal ulcers: functional morphology, the role of methods of pathogenetic therapy. Suchasna gastrojenterologija. 2013:5(73):92-103. [Article in Russian]. 